\title{
Paidéia: Management Report - 2013
}

\author{
Manoel Antônio dos Santos ${ }^{1}$ \\ Universidade de São Paulo, Ribeirão Preto-SP, Brazil
}

In this Management Report, we present indicators that give visibility to the editorial management of Paidéia for the year 2013. With the publication of this document, we preserve the tradition of presenting to the scientific community a balance of what the journal has produced in the previous year, making explicit the modus operandi of the processing of the manuscripts in the period.

The dissemination of scientific production is backed by a rigorous peer review process. To systematize information relative to the editorial process, it is possible to place the contribution of Paidéia in the contemporary scenario of scientific publications in the Humanities field, particularly Psychology.

This report is divided into the following sections: Editorial Policy and Arbitration Criteria, Editorial Process 2013, and Final Considerations.

\section{Editorial Policy and Arbitration Criteria}

Paidéia is a quarterly publication of the Graduate Psychology Program of the Faculty of Philosophy, Sciences and Letters at Ribeirão Preto, University of São Paulo FFCLRP-USP. Its editorial focus and scope is to publish Psychology related studies. The published articles should fall into the categories: research report, theoretical study, or systematic literature review. Up to 2011 the following categories of manuscripts were admitted: research report, theoretical study, professional experience report, systematic literature review, short communication, technical note, and book review. These categories are reflected in the results published in this report.

In 2014, Paideia completed 23 years of existence. Since its founding in August 1991, 55 issues have been published, from volume 1 to 23 , and its collection is fully available through free access provided by the SciELO collection. The issues are conspicuous for their diversity and breadth of topics, as well as for the plurality of methodological designs contained in the articles. The editorial line is generalist, considering the theoretical-methodological, epistemological and thematic diversity that pervades the Psychology area.

In terms of the classification in the Qualis Journals system, in the area of psychology (Qualis Journals Commission of Psychology, 2012), Paidéia ascended from the B1 stratum, its status until 2011, to A1, the highest ranking evaluation position, which demonstrates the recognition

\footnotetext{
${ }^{1}$ Correspondence address:

Manoel Antônio dos Santos. Universidade de São Paulo. Faculdade de Filosofia, Ciências e Letras de Ribeirão Preto. Departamento de Psicologia. Av. Bandeirantes, 3900. CEP 14040-901. Ribeirão Preto-SP, Brazil. E-mail: masantos@ffclrp.usp.br
}

of the prominent place that the journal occupies within the Brazilian scientific publications. This level of excellence was also verified by another important indicator - in early 2012 the journal was one of the two national publications recognized by the CAPES Support Program for the contribution to the internationalization of scientific journals in the Psychology area. This nomination was sponsored by the Qualis Journals Evaluation Committee and by the Area Evaluation Coordination (Psychology) of CAPES. The Qualis A1 classification and having been chosen by CAPES to be part of the Journal Support Program due to the potential for internationalization are achievements that consecrated Paideia as one of the leading journals in the current scenario of Psychology in the country.

The prestige given to Paidéia within the scientific community is due to its selective policy of disseminating quality knowledge. Rigorous and thorough assessment is sustained with the support of a highly qualified Editorial Board, structured according to the areas and themes addressed in the articles submitted for consideration. This Council consists of significant names of the academic community, in both the national and international contexts. The processing of the manuscripts is the responsibility of an Editorial Commission composed of Associate Editors, the majority of whom are professors linked to the Graduate Psychology Program of FFCLRP-USP. This commission coordinates the rigorous peer review process, by utilizing $\mathrm{ad}$ hoc consultants with recognized competence, who have the task of evaluating and improving the manuscripts submitted for consideration.

Toconsolidateits visibility on thenational and international level, Paidéia is indexed in 13 national and international databases (or full text portals), these being: SciELO Scientific Electronic Library Online (FAPESP/BIREME), Scopus (Elsevier), PsycINFO - Psychological Abstracts (American Psychological Association), PASCAL - L'Institut de l'Information Scientifique et Technique (INIST), LILACS Literatura Latino-Americana e do Caribe em Ciências da Saúde (Centro Latino-americano y de Caribe de Informaciones em Ciências de la Salud), CLASE - Citas Latinoamericanas en Ciências Sociales y Humanidades (Universidad Nacional Autónoma de México), PSICODOC (Colégio Oficial de Psicólogos de Madrid / Universidad Complutense de Madrid), DOAJ - Directory of Open Access Journals, Ulrich's International Periodicals Directory, Catálogo Latindex, IRESIE (Universidad Nacional Autónoma de México), Index-Psi Periódicos (CFP/PUCCAMP) and REDALYC Red de Revistas Cientificas de América Latina y el Caribe, España y Portugal. 
The submission of manuscripts is fully computerized, through the Electronic Submission system, provided by SciELO. The journal adopts a blind review evaluation system, which preserves the anonymity of the authors and reviewers. The texts submitted for consideration must primarily fall within the research report category. In each issue approximately 13 original research articles are published. From 2012, the following types of contributions were no longer accepted: reports of professional experience, brief communications, technical notes, and book reviews. As part of the new editorial policy of the journal, the Editorial Board decided to invest heavily in attracting articles that give visibility to research results derived from original empirical studies with quantitative or qualitative designs. The potential to make an impact in the area of knowledge is also a criterion for the selection of the manuscripts for publication. To be selected for publication, the manuscripts must be of international interest, rather than just local.

With regard to financing sources, Paidéia has relied on support from financial resources received annually from the Periodical Scientific Publications Support Program of USP and from the Scientific Publications Support Program of $\mathrm{CNPq}$, as well as the support of the Graduate Psychology Program of FFCLRP-USP.

The publication standards are included at the end of each issue, which are available online in the languages: Portuguese, English, and Spanish. Those standards (Instructions to the Authors) are available on the SciELO page (http://www.scielo.br/paideia). The final issue of each volume provides the list of ad hoc evaluators, who contributed to the essential task of reviewing the manuscripts during the year.

The printed version of Paidéia is distributed free to approximately 160 libraries in Brazilian public universities linked to the Brazilian Network of Psychology Libraries ReBAP. In this way, the issues are made available for the undergraduate Psychology courses and some Education courses in Brazil, as well as in other countries, such as Portugal, Spain, Mexico, France, the UK and the USA. This means that, three times a year, examples are sent to the higher education institutions of many Brazilian states and some abroad, as well as to Graduate Programs in the fields of Psychology and Education. Exchanges are also maintained with Brazilian and international Psychology and Health journals. The final issue of each volume is also sent to all the ad hoc consultants who collaborated with the journal during the year, in recognition of the collaboration provided. In this final issue (printed version) of each volume, we provide a list of ad hoc consultants who worked with the journal during the current year. It is a way of thanking those who contributed with the review of the manuscripts submitted to the journal.

Regarding the manuscript arbitration process, Paidéia adopts the mechanism of double-blind review by peers of recognized competence within the scientific community. Thus, the identities of the authors and of the ad hoc consultants are kept in strict confidentiality. The texts submitted for review should be in accordance with the guidelines of the publication standards and may be accepted or rejected by the Editorial Board, based on the recommendations of its members and the ad hoc consultants selected to enhance the evaluation process.

In relation to the availability of the content, Paidéia adopts the Creative Commons License, Attribution Noncommercial CC BY-NC. With this license it is permitted to access, download, copy, print, share, reuse, and distribute the articles, provided it is for noncommercial use and includes the citation of the source, giving appropriate credit to the journal. In such cases, no permission is required from the authors or the publishers.

The complete collection of the journal, including past issues, is available on the SciELO site, from the conversion of the archives to the standard used by this database, thus increasing the visibility of the articles published, in accordance with the policy of free and universal access to the contents of the journal.

Another aspect that differentiates Paidéia in the scenario of Psychology publications is the systematic and periodic provision of information regarding the management process of the journal. In the first issue of each volume/year we publish a Management Report, in which we seek to provide visibility and transparency to the work consolidated in the previous year. This document contains objective indicators to measure the progress of the journal, such as the processing time of the manuscripts, the origin of the authors who have their articles published, and the institutional origins of the reviewers/ad hoc consultants, among other topics of interest (Santos 2010, 2011, 2012, 2013).

\section{Editorial Process - 2013}

When considering the editorial process of Paidéia in 2013 , it can be observed that the average processing time of the manuscripts was approximately 12 months. In this year, the journal received 102 new manuscripts, of which 27 were approved, 40 rejected and 35 were still in the evaluation process in January 2014, when this report was written (Table 1). Considering the manuscripts for which the editorial process was terminated in $2013(n=67)$, the journal approved $40.3 \%$ and rejected $59.7 \%$.

In contrast to the boom of submissions recorded in 2012 (156 manuscripts), an increase of approximately $63 \%$ over the previous year (99 manuscripts), the number of articles submitted in 2013 (102) returned to the 2011 level. This decrease can be partly attributed to the full implementation of the new publication standards of the journal, which include, in addition to more stringent quality criteria, the system of publication in the English language, with the financial costs of the translation, performed by qualified experts, covered exclusively by the authors. 
Table 1

Editorial situation of the Manuscripts Submitted to Paidéia in 2013

\begin{tabular}{lc}
\hline Final decision & $N$ \\
\hline Received (Total) & 102 \\
\hline Approved & 27 \\
Rejected & 40 \\
In the editorial process & 35 \\
\hline Note. Time between submission and publication in 2013 = 12 months.
\end{tabular}

Manuscripts submitted in 2013 were classified in the following categories: (a) Research report (85\%); (b) Theoretical study (7\%); (c) Systematic literature review $(8 \%)$, as presented in Table 2 .

In 2013, in volume 23 (issues 54, 55 and 56), 39 articles and two systematic reviews were published, as well as three editorials and one management report. The publications were classified into the following categories: (a) Research report (95\%) and (b) Systematic literature review (5\%), as presented in Table 3.

Figure 1 shows the evolution of the number of manuscripts submitted and their fate in the triennium 2011-2013. In 2013, as mentioned above, there was a decrease in the number of manuscripts submitted to Paideia, returning to the 2011 level of

Table 2

Editorial situation of the Manuscripts Submitted to Paidéia in 2013

\begin{tabular}{lcc}
\hline Type of manuscript & $n$ & $\%$ \\
\hline Research report & 87 & 85 \\
Theoretical study & 7 & 7 \\
Systematic literature review & 8 & 8 \\
Total & 102 & 100 \\
\hline
\end{tabular}

submission. Accompanying the lower flow of new manuscripts, the amount of rejected works, and articles published also decreased. The difference between articles published and refused remained the same proportionally, which indicates that the rigor in the analysis of the manuscripts was maintained.

Table 3

Category of the Manuscripts Published in Paidéia in 2013

\begin{tabular}{lcc}
\hline Type of manuscript & $n$ & $\%$ \\
\hline Research report & 37 & 95 \\
Systematic literature review & 2 & 5 \\
Total & 39 & 100 \\
\hline
\end{tabular}

Regarding the institutional affiliation of the authors, Table 4 shows that Paidéia published articles originating from 27 Brazilian universities/colleges/institutes, with a slight predominance of the Federal University of São Carlos.
There was a reasonable increase in the amount of articles with authors affiliated with international institutional, mainly from Portugal. It should be noted that the authors of the published articles are linked to a variety of higher education institutions, public, private and confessional, of various states

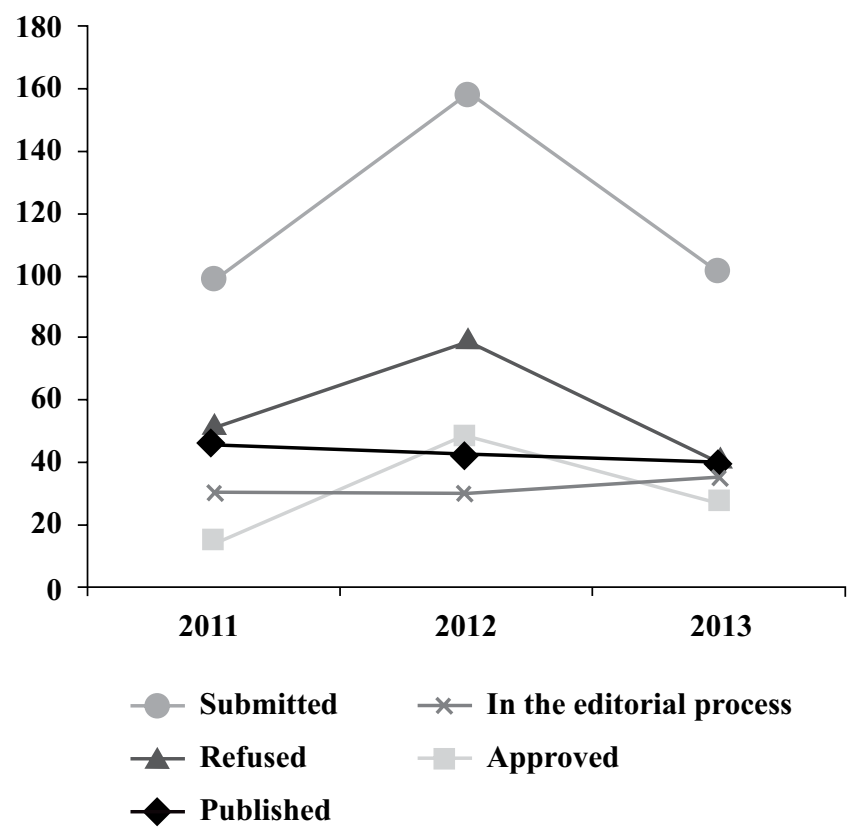

Figure 1. Number of manuscripts submitted to Paidéia and their editorial outcome in the triennium 2011-2013.

of the Brazilian federation and abroad. There was again a predominance of federal universities in relation to state ones.

Table 5 presents data relating to the body of ad hoc consultants of Paidéia, highlighting the country and region of origin.

Regarding the origins of the ad hoc consultants, the predominance should be noted of reviewers from the universities of São Paulo (61\%) which, added to the evaluators from other institutions within the Southeast, totaled $72.7 \%$ of the body of reviewers. The Northeastern region contributed $5.2 \%$ of the ad hoc evaluators, the same percentage as the Central-West; while the Southern region had a participation of $3.9 \%$ and the Northern region $2.6 \%$. Furthermore, the important collaboration of international evaluators can be noted, $10.4 \%$ (Table 5).

Figure 2 shows the percentile distribution of the ad hoc consultants according to geographic origin.

\section{Final Considerations}

This management report systematizes information that permits the mapping of the framework of the editorial processing of the manuscripts submitted to the Paidéia during the year 2013. Comparison of the data accumulated over the last three years shows that the journal has gradually and consistently strengthened its editorial process, establishing 
Table 4

Institutional Origin of the authors who published in Paidéia in 2013

\begin{tabular}{|c|c|c|}
\hline National institutions & $n$ & $\%$ \\
\hline Universidade Federal de São Carlos - SP & 19 & 19.0 \\
\hline Universidade Federal do Rio Grande do Sul - RS & 14 & 14.0 \\
\hline Universidade São Francisco - SP & 10 & 9.9 \\
\hline Universidade de São Paulo - SP & 10 & 9.9 \\
\hline Pontifícia Universidade Católica - SP, MG, RS, GO & 6 & 6.0 \\
\hline Universidade Federal de Juiz de Fora - MG & 5 & 5.0 \\
\hline Universidade Federal de Santa Catarina - SC & 4 & 3.9 \\
\hline Universidade Federal da Bahia - BA & 4 & 3.9 \\
\hline Universidade do Estado do Rio de Janeiro - RJ & 4 & 3.9 \\
\hline Universidade Federal de Santa Maria - RS & 4 & 3.9 \\
\hline Universidade Federal da Paraná - PR & 2 & 1.9 \\
\hline Universidade Estadual de Campinas - SP & 2 & 1.9 \\
\hline Universidade Federal do Rio Grande do Norte - RN & 2 & 1.9 \\
\hline Universidade Estadual de Campinas - SP & 2 & 1.9 \\
\hline Universidade Estadual de Londrina - PR & 1 & 1.0 \\
\hline Universidade do Federal do Rio de Janeiro - RJ & 1 & 1.0 \\
\hline Universidade de Brasília - DF & 1 & 1.0 \\
\hline Universidade Federal do Espírito Santo - ES & 1 & 1.0 \\
\hline Universidade Federal da Paraíba - PB & 1 & 1.0 \\
\hline Universidade Estadual Paulista - SP & 1 & 1.0 \\
\hline Universidade Federal de Sergipe - SE & 1 & 1.0 \\
\hline Universidade Federal do Recôncavo da Bahia - BA & 1 & 1.0 \\
\hline Faculdade de Ilhéus - BA & 1 & 1.0 \\
\hline Universidade Paulista - SP & 1 & 1.0 \\
\hline Universidade Federal do Pará - PA & 1 & 1.0 \\
\hline Instituto da Família de Porto Alegre - RS & 1 & 1.0 \\
\hline $\begin{array}{l}\text { Universidade Estadual de Ciências da Saúde de } \\
\text { Alagoas - AL }\end{array}$ & 1 & 1.0 \\
\hline Total & 101 & 100 \\
\hline International institutions & $\mathrm{n}$ & $\%$ \\
\hline Universidade de Porto, Portugal & 3 & 34 \\
\hline Universidade de Coimbra, Portugal & 2 & 22 \\
\hline Universidade Atlântica, Portugal & 1 & 11 \\
\hline Université du Québec à Montréal, Canadá & 1 & 11 \\
\hline University of Alabama, USA & 1 & 11 \\
\hline Keele University, United Kingdom & 1 & 11 \\
\hline Total & 9 & 10 \\
\hline
\end{tabular}

itself as a unifying space for the knowledge produced in the field of Psychology. However, fragilities exist that need to be considered, such as the slowness in the process of evaluation of the manuscripts (that has been gradual overcome with some changes implemented in the on-line submission process via Submission), the low percentage of articles from foreign authors, and the concentration of ad hoc consultants in the Southeastern Region states. Overcoming these challenges requires the adoption of specific strategies.

One positive aspect to be highlighted in this report is the adoption of the publication of the full text of the articles
Table 5

Distribution of the ad hoc Consultants of Paidéia According to their Geographic Origin $(n=76)$

\begin{tabular}{lcc}
\hline International Country & $n$ & $\%^{*}$ \\
\hline United Kingdom & 1 & 1.3 \\
USA & 1 & 1.3 \\
Canada & 2 & 2.6 \\
France & 1 & 1.3 \\
Portugal & 3 & 3.9 \\
Subtotal & 8 & 10.4 \\
\hline National State & $\mathrm{n}$ & $\%^{*}$ \\
\hline Southeastern Region & & \\
São Paulo & 46 & 61.0 \\
Rio de Janeiro & 2 & 2.6 \\
Minas Gerais & 4 & 5.2 \\
Espírito Santo & 3 & 3.9 \\
Subtotal & 55 & 72.7 \\
Southern Region & & \\
Rio Grande do Sul & 2 & 2.6 \\
Santa Catarina & 1 & 1.3 \\
Subtotal & 3 & 3.9 \\
Northeastern Region & & \\
Bahia & 1 & 1.3 \\
Pernambuco & 1 & 1.3 \\
Rio Grande do Norte & 2 & 2.6 \\
Subtotal & 4 & 5.2 \\
Central-Western Region & & \\
Federal District & 2 & 2.6 \\
Mato Grosso & 1 & 1.3 \\
Mato Grosso do Sul & 1 & 1.3 \\
Subtotal & 4 & 5.2 \\
Northern Region & & \\
Pará & 2 & 2.6 \\
Subtotal & 2 & 2.6 \\
\hline Calcution & & \\
\hline & &
\end{tabular}

* Calculation based on the total of 76 advisors who collaborated with the journal in 2013.

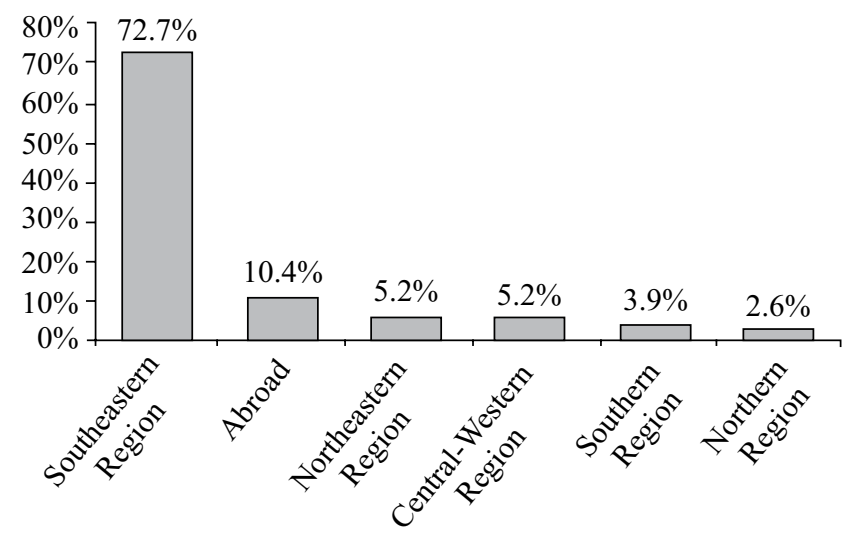

Figure 2. Distribution of the ad hoc consultants who collaborated with Paidéia in 2013 according to their region of origin. 
in English, which gives greater international visibility to the articles published in the journal. The journal has ensured its inclusion in new international indexes, which contributes to the internationalization efforts.

Another positive point is that the rate of "endogeneity" of the journal (articles from authors of the University of São Paulo) $-9.9 \%$ of the articles published in 2013 - remained stable, when considering the historical series. This rate was $3.3 \%$ in 2012 (Santos, 2013), 9.6\% in 2011 (Santos, 2012), $9.7 \%$ in 2010 (Santos, 2011), and $18.0 \%$ in 2009 (Santos, 2010).

As a result of the continuing efforts that have been systematically undertaken over the last few years, Paidéia today occupies a prominent place among the publications in the field of psychology, among the three national journals in the area classified as A1 (Qualis Journals Commission of Psychology, 2012). The introduction of the online submission represented a substantial gain for the organization and management of the flow of information, helping to decrease the time of publication, however, is still far from ideal and should be continuously improved. Investments to increase the visibility of the journal in the international context are needed, to attract articles from foreign researchers, to amplify the indexation in international databases, and to enhance the bibliometric indicators.

Regarding the communication of science, it must be remembered that the publication may be through various means, with scientific journals highlighted due to quality control, greater credibility, consistency, and visibility of information. Scientific knowledge is mainly derived from original research, submitted to the peer review process and published in an indexed journal, with attention to the use and impact of the information conveyed. Being indexed in specialized or multidisciplinary databases is the seal of quality of a journal.

The issue of the native language being privileged in the publication remains a constraint to increasing the visibility of articles published by the national journals. For years Paidéia has been publishing abstracts in Portuguese, English and Spanish, which always constituted a difference compared to other journals in the field of psychology, which traditionally only require the abstract in Portuguese and English. In 2012 we implemented the bilingual publication of articles, i.e., we provided the electronic library (SciELO) with the full versions in Portuguese and English, following the example of journals from other fields of knowledge. From the second issue of 2013, the articles began to be published in English only, in the printed version as well as the online version. In this way, we are gradually fulfilling the goals established so that Paidéia can contribute to the production of knowledge in Psychology that can achieve the desirable international levels of excellence and be profiled with other more advanced areas of knowledge.

Considering the great increase in the national scientific production in recent years, due to a stimulus policy that is unfortunately often confused with the deleterious productivism resulting from the pressure to publish, it is highly desirable for national journals to give greater transparency to their publishing processes. Thus, this Management Report complies with the social mission of returning to society the result of public investments that have been allocated in recent years to the field of science and technology. Finally, the scientific journals play an important role in evaluating the quality and dissemination of the knowledge produced in the area of Psychology. They are the principle means of publication and also the most prestigious and credible.

\section{References}

Comissão Qualis Periódico da Psicologia (2012). Comunicado $n^{\circ}$ 0001/2012 - Área de Psicologia: Atualização do webqualis da área. Brasília: Coordenação de Aperfeiçoamento de Pessoal de Nível Superior. Retrieved from http://www.capes.gov.br/images/stories/ download/avaliacao/Qualis___Psicologia.pdf

Santos, M. A. (2011). Paidéia: Relatório de gestão - 2010. Paidéia, 21(48), 5-8.

Santos, M. A. (2012). Paidéia: Relatório de gestão - 2011. Paidéia, 22(51), 5-9.

Santos, M. A. (2013). Paidéia: Relatório de gestão - 2012. Paidéia, 23(54), 3-7.

Manoel Antônio dos Santos is an Associate Professor of the Faculdade de Filosofia, Ciências e Letras de Ribeirão Preto of the Universidade de São Paulo, and Editor of Paidéia.

\section{How to cite this management report:}

Santos, M. A. (2014). Paidéia: Management report - 2013. Paidéia (Ribeirão Preto), 24(57), 5-9. doi:10.1590/1982-43272457201402 


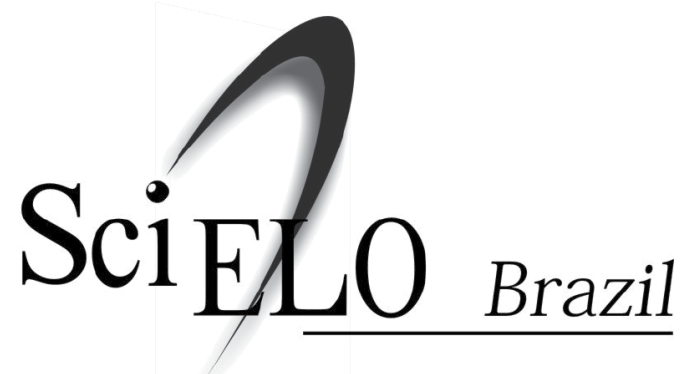

Paidéia (Ribeirão Preto) is a four-monthly publication available in full-text in the Scientific Electronic Library Online - SciELO.

The SciELO interface provides easy access to the tables of content and to the full-text articles.

The SciELO interface also provides the retrieval of articles by the author's name, the words from title, abstract and descriptors, in addition to providing bibliometric indicators and consultation indicators.

The articles are enriched with connections to the LILACS, MEDLINE and PubMed databases.

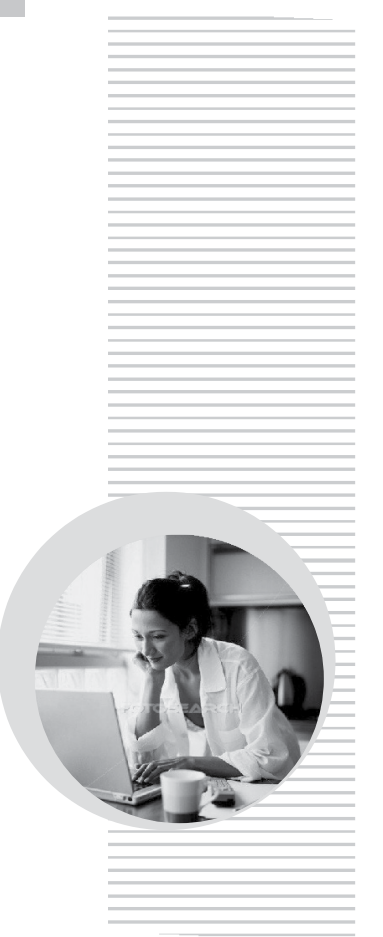

Paidéia (Ribeirão Preto) is a part of SciELO Brazil:

\section{www.scielo.br/paideia}

The SciELO interface provides access to a network of SciELO websites, gathering the major scientific journals of Latin America, Caribbean, Spain, Portugal and South Africa:

\section{www.scielo.org}

The electronic library is a project developed by the São Paulo Research Foundation (FAPESP), in partnership with the Latin American and Caribbean Center on Health Sciences Information (BIREME) and the National Council for Scientific and Technological Development (CNPq). 